\title{
Risk Factors for Infection with Soil Transmitted Helminths, Cryptosporidium spp., and Giardia duodenalis in Children Enrolled in Preschools in Kafue District, Zambia
}

\author{
Joyce Siwila $^{1}$ and Annette Olsen ${ }^{2}$ \\ ${ }^{1}$ Department of Clinical Studies, School of Veterinary Medicine, University of Zambia, P.O. Box 32379, Lusaka, Zambia \\ ${ }^{2}$ Parasitology and Aquatic Diseases, Department of Veterinary Disease Biology, University of Copenhagen, Dyrlaegevej 100, \\ 1870 Frederiksberg C, Denmark
}

Correspondence should be addressed to Joyce Siwila; siwilaj@yahoo.co.uk

Received 16 December 2014; Accepted 17 March 2015

Academic Editor: How-Ran Guo

Copyright (c) 2015 J. Siwila and A. Olsen. This is an open access article distributed under the Creative Commons Attribution License, which permits unrestricted use, distribution, and reproduction in any medium, provided the original work is properly cited.

\begin{abstract}
Intestinal parasitic infections are common among children worldwide. This study was aimed at determining risk factors for infection with soil transmitted helminths, Cryptosporidium spp., and Giardia duodenalis, among children in preschools. The study was in two parts: a cross-sectional study in which data were collected from 403 children from 10 preschools and a longitudinal study in which 100 children from four preschools from the previous 10 were selected. Prevalence of Ascaris lumbricoides was $12.0 \%$, while that of hookworm was $8.3 \%$. Overall prevalence of Cryptosporidium and G. duodenalis was $28.0 \%$ and $29.0 \%$, respectively. Low education level of parent/guardian was a significant risk factor for $A$. lumbricoides $(\mathrm{OR}=2.35,95 \% \mathrm{CI}: 1.02-5.41 ; P=0.04)$, while roofing types other than corrugated iron sheets were found to be protective for $G$. duodenalis infection in both bivariate and multivariate analyses (multivariate: $\mathrm{OR}=0.67,95 \% \mathrm{CI}: 0.45-0.99 ; P=0.04$ ). Low socioeconomic level was found to be protective for Cryptosporidium spp. infection in multivariate analysis $(\mathrm{OR}=0.59,95 \% \mathrm{CI}: 0.35-0.99 ; P=0.04)$. In the longitudinal study, none of the factors were associated with either infection. These findings may have implications for other preschools in other districts in Zambia.
\end{abstract}

\section{Introduction}

Soil transmitted helminths (STHs) are widely distributed throughout the tropics and subtropics, and determinants of transmission include adequate moisture and warm temperature [1]. Transmission is enhanced by poor socioeconomic conditions, deficiencies in sanitary facilities, insufficient supplies of portable water, poor personal hygiene, lack of education, and substandard housing $[2,3]$. Other environmental factors in the public domain such as the presence of drainage and sewerage contribute to variation in exposure [4]. Risk groups include school-age children (ascariasis, hookworm, and trichuriasis), adolescent girls and women of reproductive age (hookworm infection) [5]. Globally, STHs are reported to infect more than a billion yearly [6]. In 2010, an estimated 439 million people were reported to be infected with hookworm, 819 million with Ascaris lumbricoides, and 465 million with Trichuris trichiura [7].
Infection with the enteric protozoan parasites Cryptosporidium spp. and Giardia is common among children in the developed and developing world, especially in daycare centres [8]. Transmission is by the faecal-oral route [9], and household animals, such as dogs, cats, and birds, may contribute to the transmission because of their close association with their owners [10]. The most common risk factors for cryptosporidiosis are concurrent immunosuppressive disease, age, travel (particularly international travel), and direct or indirect contact to farm animals [11]. Close contact between humans especially under poor hygienic conditions favours transmission $[12,13]$.

Giardia duodenalis infection is also associated with poor sanitary conditions, insufficient water treatment, and crowding in day-care centres and institutional facilities like nursing homes [14]. Infants, children in day-care centres, child care providers, parents with infected children, swimmers, 
travellers, and immune compromised individuals are at risk $[15,16]$.

Zambia, like any other developing country, is not free from poor sanitary conditions, insufficient water supply, and disadvantaged communities. Local factors that may influence infection with STHs have not been explored. There is, however, few data regarding the probable factors of infection with the protozoan parasites, with one study reporting no association between Cryptosporidium infection and keeping animals, nutritional status, or parental education [17]. The current study was conducted to determine the risk factors for infection with STHs, Cryptosporidium spp. and Giardia duodenalis in children enrolled in the selected preschools in Kafue district of Zambia.

\section{Materials and Methods}

2.1. Study Area. The study was done in Kafue District in Zambia from June 2007 to September 2008. The district is located $45 \mathrm{~km}$ south of Lusaka, the capital of Zambia, and has a population of approximately 227,466 people. The main ethnic groups are Nyanja, Bemba, and Tonga, with Nyanja being used as the main language of communication. More than 13\% of the population is unemployed, but most of these people are involved in small-scale farming. The main crop grown is maize [18]. The district had 21 registered preschools distributed in different townships, and each school had an average of 50 enrolled children. Ten of these preschools were randomly selected to participate in the study. Of the ten selected schools, two were privately owned, three were community schools managed by the community in which they were located, and five were managed by nongovernmental organizations (NGOs).

2.2. Study Design, Population, and Data Collection. Collection of epidemiological data was done in two parts/phases. In the first phase, a cross-sectional baseline study was conducted over a 3-month period (June-August, 2007) in which 10 preschools were randomly selected and enrolled. From each school, 50 children were randomly selected. Out of the 500 children enrolled, data was collected from 403 children. Questionnaires were used to collect demographic and socioeconomic data, which included highest level of education attained by parent/guardian, number of people living in the household, presence of toilet, drinking water source, roofing material of the house, and socioeconomic level. The socioeconomic level was based on whether they lived in an electrified house and whether they owned a refrigerator, radio, television, phone, or a bicycle, and the levels were classified as low (if they owned up to two items) and high (if they owned 3-6 items). This part of the study was aimed at identifying the risk factors for infection with STHs and the intestinal protozoa Cryptosporidium spp. and Giardia.

In the second phase of the study, four preschools out of the 10 from the first phase were selected for further studies due to their high prevalence of Cryptosporidium spp. and Giardia infections. A total of 100 children (25 children per school) were included in the study. The study was aimed at determining the incidence, seasonal prevalence of these two parasites, and associated risk factors. Questionnaires were administered to collect information on whether the household treated the drinking water or not, the treatment methods, presence of animals, and consumption of uncooked vegetables. Monthly follow-up visits were made for a period of 12 months (October 2007-September 2008) and stool samples were collected from the children during each visit. Parents/ guardians were the principle respondents in both studies. Stool sample analysis and results are reported by Siwila et al. $[19,20]$.

2.3. Ethical Considerations. Ethical approval was obtained from the University of Zambia Biomedical Research Ethics Committee, Lusaka, Zambia, and the Danish National Committee on Biomedical Research Ethics, Copenhagen, Denmark, recommended the study. Permission to conduct the study in the schools was sought from the preschool head teachers and the children were enrolled in the study after obtaining written informed consent from their parents/ guardians.

2.4. Statistical Analysis. Statistical analyses were carried out using computer software STATA Version 10.1 (StataCorp, College Station, Texas, USA) and SPSS Version 11 (Statistical Package for Social Sciences). Associations between factors and infection with helminths and the two protozoa were compared by logistic regression and odds ratio and $P$ values reported. Adjusting for the clustering effect of schools was done in all analyses. The data are reported as percentages or absolute values. Chi-square and Fisher's exact tests were applied where appropriate. All results were considered significant if $P<0.05$.

\section{Results}

3.1. Prevalence of Soil Transmitted Helminths (Part I). Of the 403 children included in the study, 172 were males and 231 were females. The prevalence of intestinal parasites (STHs, Cryptosporidium spp. and Giardia) and age distribution are reported elsewhere [19]. Briefly, the prevalence of Ascaris lumbricoides was found to be $12.0 \%$, while that of hookworm was $8.3 \%$. Trichuris trichiura was not found in any of the samples analysed. The overall prevalence of Cryptosporidium spp. was $28.0 \%$ and that of Giardia duodenalis was $29.0 \%$.

3.2. Distribution of Risk Factors. Thirteen parents did not respond completely to the questionnaires; these were excluded from further analysis. Table 1 indicates the distribution of the risk factors for the remaining 390 respondents. Ownership of a refrigerator, radio, television, phone, and bicycle and having an electrified house were used to classify socioeconomic level as described above. When these were classified into two categories of socioeconomic level, more than half of the households were classified as "low socioeconomic level" (52.3\%; 204/390).

Two preschools, out of the 10 preschools, were not included in the analysis of helminth infections because the children were treated with antihelminthics a week prior to sample collection. Therefore, analysis was done on 
TABLE 1: Distribution of risk factors from 390 parents/guardians (respondents) for the children enrolled in preschools in Kafue district, Zambia.

\begin{tabular}{|c|c|c|}
\hline Factor/response & Number of responses & $\%$ \\
\hline \multicolumn{3}{|l|}{ Educational level } \\
\hline Tertiary & 22 & 5.6 \\
\hline Secondary & 181 & 46.4 \\
\hline Primary & 161 & 41.3 \\
\hline None & 26 & 6.7 \\
\hline \multicolumn{3}{|l|}{ Water source } \\
\hline Municipal $^{1}$ & 312 & 80.0 \\
\hline Well & 78 & 20.0 \\
\hline \multicolumn{3}{|c|}{ Number of people in household } \\
\hline$\leq 3$ & 245 & 62.8 \\
\hline$>3$ & 145 & 37.2 \\
\hline \multicolumn{3}{|l|}{ Had a toilet ${ }^{2}$} \\
\hline Yes & 334 & 85.6 \\
\hline No & 56 & 14.4 \\
\hline \multicolumn{3}{|l|}{ Roofing type } \\
\hline Iron sheets & 258 & 66.1 \\
\hline Asbestos & 71 & 18.2 \\
\hline Tiles & 51 & 13.1 \\
\hline Grass & 10 & 2.6 \\
\hline \multicolumn{3}{|l|}{ Household with } \\
\hline Electricity & 113 & 29.0 \\
\hline Refrigerator & 76 & 19.5 \\
\hline Radio & 265 & 67.9 \\
\hline Television (TV) & 170 & 43.6 \\
\hline Phone & 190 & 48.7 \\
\hline Bicycle & 187 & 47.9 \\
\hline
\end{tabular}

${ }^{1}$ Municipal water source was supplied by one water supply company.

${ }^{2} 85.3 \%$ owned pit latrines, while the rest owned flushing toilets inbuilt in the house.

the eight remaining preschools with 311 children. Tables 2 and 3 indicate the factors studied, the number of cases, odds ratios, 95\% confidence intervals, and the associated $P$ values for A. lumbricoides, hookworm, Cryptosporidium spp., and G. duodenalis, respectively.

Out of the factors studied, parent/guardian level of education was significantly associated with A. lumbricoides infection after controlling for the clustering effect of school (Table 2). Thus, a child having a parent/guardian with none or only a primary education had a 2.35 higher risk of being infected with A. lumbricoides compared to a child with parents/guardians having a higher education. The OR of education did not change when the other possible risk factors were controlled in a multivariate analysis, but the $P$ value became just insignificant $(P=0.06)$. None of the factors studied were associated with hookworm infection. For the protozoan parasites, none of the investigated factors was significantly associated with Cryptosporidium spp. infection in the bivariate analyses (Table 3), but socioeconomic level was significantly associated with this infection in the multivariate analysis (Table 4 ), where the other possible risk factors were controlled for. Thus, unexpectedly, children living in a household with a low socioeconomic level as defined by the present study had nearly half the risk $(\mathrm{OR}=0.59)$ of being infected with Cryptosporidium spp. compared to those from households with a higher socioeconomic level. Having a house with corrugated iron roofing was significantly associated with Giardia infection (Table 3), even after controlling for other factors (Table 4). Thus, those living in houses with other roof types than corrugated iron sheets had a decreased risk of being infected with Giardia compared to those living in houses with iron sheet roofs.

3.3. Prevalence of Cryptosporidium and Giardia (Part II). Of the 100 children included in this part of the study, 38 were males and 62 were females. A total of $86 \%$ experienced one or more episodes of Cryptosporidium infection, while $75 \%$ had one or more infections with $G$. duodenalis. From this second phase of the study, incidence and seasonal prevalence of Cryptosporidium and Giardia were determined. The details of the prevalence, incidence, age distribution, and seasonal prevalence are reported elsewhere [20].

3.4. Distribution of Risk Factors. The factors studied were treatment of drinking water and treatment methods, keeping of domestic animals, and consumption of uncooked vegetables. Only 28 respondents reported that they treated their water by chlorination, and the rest did nothing. Fortyfive children came from homes where domestic animals were kept and these could be pigs, dogs, goats, chickens, ducks, or pigeons. Only seven respondents reported that they sometimes consumed uncooked vegetables in their households and all children from these homes were infected with Cryptosporidium spp. infection but with no significant association (Table 5). Moreover, out of the same seven respondents, six also had G. duodenalis infection. Similarly, there was no significant association between infection and consumption of uncooked vegetables. The number of cases of Cryptosporidium spp. and Giardia associated with each risk factor and the associated $P$ values are tabulated in Table 5 . None of the factors had any significant association with either infection. However, when schools were considered separately, animal keeping was found to be associated with $G$. duodenalis infection in one school $(P=0.03)$.

\section{Discussion}

The present study explored the factors that may be associated with infection with STHs, Cryptosporidium spp. and Giardia in preschool children. The level of education of the parent/guardian was found to be significantly associated with A. lumbricoides infection, with infection being significantly higher in those children whose parent/guardian had none or only primary education. This is in accordance to what is commonly known that the greater the level of education of parent/guardian, the lower the presence of enteroparasites, as the literate parents are known or expected to be able to practice better hygiene as compared to illiterate ones, thereby preventing/reducing transmission of infection. The findings of this study complement those from a study in Brazil which 
TABLE 2: Distribution of factors, odds ratio (OR), and 95\% confidence intervals (95\% CI) for infection with Ascarislumbricoides and hookworm among 311 children from eight Zambian preschools (bivariate analyses).

\begin{tabular}{|c|c|c|c|c|c|c|c|}
\hline \multirow{2}{*}{ Factor } & \multirow{2}{*}{$N$} & \multicolumn{3}{|c|}{ Ascaris lumbricoides } & \multicolumn{3}{|c|}{ Hookworm } \\
\hline & & Infected & OR $(95 \% \mathrm{CI})^{1}$ & $P$ & Infected & OR $(95 \% \mathrm{CI})^{1}$ & $P$ \\
\hline \multicolumn{8}{|l|}{ Education level } \\
\hline Secondary/tertiary & 160 & 13 & 1.00 & \multirow{2}{*}{0.04} & 11 & 1.00 & \multirow{2}{*}{0.19} \\
\hline None/primary & 151 & 26 & $2.35(1.02-5.41)$ & & 16 & $1.61(0.79-3.25)$ & \\
\hline \multicolumn{8}{|c|}{ Number of people in $\mathrm{h} / \mathrm{hold}$} \\
\hline$\leq 3$ & 196 & 23 & 1.00 & \multirow{2}{*}{0.47} & 21 & 1.00 & \multirow{2}{*}{0.19} \\
\hline$>3$ & 115 & 16 & $1.22(0.71-2.07)$ & & 6 & $0.46(0.14-1.46)$ & \\
\hline \multicolumn{8}{|l|}{ Presence of a toilet } \\
\hline Yes & 269 & 32 & 1.00 & \multirow{2}{*}{0.57} & 24 & 1.00 & \multirow{2}{*}{0.84} \\
\hline No & 42 & 7 & $1.48(0.38-5.75)$ & & 3 & $0.79(0.08-8.18)$ & \\
\hline \multicolumn{8}{|c|}{ Drinking municipal water } \\
\hline No & 15 & 2 & 1.00 & \multirow{2}{*}{0.86} & 2 & 1.00 & \multirow{2}{*}{0.37} \\
\hline Yes & 296 & 37 & $0.93(0.40-2.15)$ & & 25 & $0.60(0.20-1.82)$ & \\
\hline \multicolumn{8}{|l|}{ House roofing type } \\
\hline Corrugated iron & 210 & 30 & 1.00 & \multirow{2}{*}{0.34} & 21 & 1.00 & \multirow{2}{*}{0.23} \\
\hline Other types & 101 & 9 & $0.59(0.20-1.75)$ & & 6 & $0.57(0.23-1.42)$ & \\
\hline \multicolumn{8}{|l|}{ Socioeconomic level } \\
\hline High & 164 & 21 & 1.00 & \multirow{2}{*}{0.91} & 17 & 1.00 & \multirow{2}{*}{0.17} \\
\hline Low & 147 & 18 & $0.95(0.38-2.37)$ & & 10 & $0.63(0.33-1.21)$ & \\
\hline
\end{tabular}

${ }^{1}$ Adjusting for the clustering effect of schools was done in all analyses.

TABLE 3: Distribution of factors, odds ratio (OR), and 95\% confidence intervals (95\% CI) for infection with Cryptosporidium spp. and Giardia among 390 children from ten Zambian preschools (bivariate analyses).

\begin{tabular}{|c|c|c|c|c|c|c|c|}
\hline \multirow{2}{*}{ Factor } & \multirow{2}{*}{$N$} & \multicolumn{3}{|c|}{ Cryptosporidium spp } & \multicolumn{3}{|c|}{ G. duodenalis } \\
\hline & & Infected & OR $(95 \% \mathrm{CI})^{1}$ & $P$ & Infected & OR $(95 \% \mathrm{CI})^{1}$ & $P$ \\
\hline \multicolumn{8}{|l|}{ Education level } \\
\hline Secondary/tertiary & 203 & 56 & 1.00 & \multirow{2}{*}{0.85} & 54 & 1.00 & \multirow{2}{*}{0.60} \\
\hline None/primary & 187 & 53 & $1.04(0.71-1.51)$ & & 53 & $1.09(0.78-1.52)$ & \\
\hline \multicolumn{8}{|c|}{ Number of people in h/hold } \\
\hline$\leq 3$ & 244 & 65 & 1.00 & \multirow{2}{*}{0.65} & 69 & 1.00 & \multirow{2}{*}{0.66} \\
\hline$>3$ & 146 & 44 & $1.19(0.56-2.51)$ & & 38 & $0.89(0.54-1.47)$ & \\
\hline \multicolumn{8}{|l|}{ Presence of a toilet } \\
\hline Yes & 334 & 93 & 1.00 & \multirow{2}{*}{0.89} & 95 & & \multirow{2}{*}{0.19} \\
\hline No & 56 & 16 & $1.04(0.63-1.70)$ & & 12 & $0.69(0.39-1.20)$ & \\
\hline \multicolumn{8}{|c|}{ Drinking municipal water } \\
\hline No & 78 & 23 & 1.00 & \multirow{2}{*}{0.82} & 19 & 1.00 & \multirow{2}{*}{0.40} \\
\hline Yes & 312 & 86 & $0.91(0.41-2.01)$ & & 88 & $1.22(0.77-1.93)$ & \\
\hline \multicolumn{8}{|l|}{ House roofing type } \\
\hline Corrugated iron & 258 & 77 & 1.00 & \multirow{2}{*}{0.46} & 78 & 1.00 & \multirow{2}{*}{0.04} \\
\hline Other types & 132 & 32 & $0.75(0.35-1.60)$ & & 29 & $0.65(0.42-0.99)$ & \\
\hline \multicolumn{8}{|l|}{ Socioeconomic level } \\
\hline High & 186 & 61 & 1.00 & \multirow{2}{*}{0.14} & 59 & 1.00 & \multirow{2}{*}{0.26} \\
\hline Low & 204 & 48 & $0.63(0.34-1.16)$ & & 54 & $0.77(0.50-1.21)$ & \\
\hline
\end{tabular}

${ }^{1}$ Adjusting for the clustering effect of schools was done in all analyses.

reported high presence of enteroparasites (80\%) in children with illiterate mothers as compared to those with literate ones (26.3\%) [21]. Two studies in Ecuador also reported similar findings [22, 23] with Menzies et al. [23] reporting a strong association between soil transmitted helminths and low maternal educational level.

Low socioeconomic level, compared to high socioeconomic level, was associated with a decrease in risk of 
TABLE 4: Risk factors for infection with Cryptosporidium spp. and Giardia in Kafue, Zambia, in 390 children (multivariate logistic regression analyses adjusting for the clustering effect of school).

\begin{tabular}{lccc}
\hline Parasite & Variable & Odds ratio & $95 \%$ CI \\
Cryptosporidium & High socioeconomic level & 1.00 & $0.35-0.99$ \\
& Low socioeconomic level & 0.59 & 0.04 \\
\multirow{2}{*}{ Giardia } & Corrugated iron roof & 1.00 & 0.67 \\
& Other types & $0.45-0.99$ & 0.04 \\
\hline
\end{tabular}

TABLE 5: Distribution of factors for infection with Cryptosporidium spp. and G. duodenalis among 100 children from four Zambian preschools.

\begin{tabular}{|c|c|c|c|c|c|}
\hline \multirow{2}{*}{ Factor } & \multirow{2}{*}{$N$} & \multicolumn{2}{|c|}{ Cryptosporidium spp. } & \multicolumn{2}{|c|}{ G. duodenalis } \\
\hline & & Number of cases & $P$ value & Number of cases & $P$ value \\
\hline \multicolumn{6}{|c|}{ Treat drinking water } \\
\hline Yes & 28 & 25 & \multirow{2}{*}{0.75} & 21 & \multirow{2}{*}{1.00} \\
\hline No & 72 & 61 & & 54 & \\
\hline \multicolumn{6}{|c|}{ Treatment methods } \\
\hline Boiling & 0 & 0 & \multirow{3}{*}{0.75} & 0 & \multirow{3}{*}{1.00} \\
\hline Chlorination & 28 & 25 & & 21 & \\
\hline Nothing & 72 & 61 & & 54 & \\
\hline \multicolumn{6}{|l|}{ Keep animals } \\
\hline Yes & 45 & 38 & \multirow{2}{*}{0.69} & 31 & \multirow{2}{*}{0.20} \\
\hline No & 55 & 48 & & 44 & \\
\hline \multicolumn{6}{|c|}{ Eat uncooked veges ${ }^{\mathrm{a}}$} \\
\hline Yes & 7 & 7 & \multirow{2}{*}{0.59} & 6 & \multirow{2}{*}{0.68} \\
\hline No & 93 & 79 & & 69 & \\
\hline
\end{tabular}

${ }^{\mathrm{a}}$ Vegetables.

Cryptosporidium spp. infection, a finding that is in contrast to most studies that report associations between low socioeconomic level and Cryptosporidium spp. infection [21, 24]. In these studies, family/household income was used as a measure of socioeconomic status, while in the present study, items owned were used, and this could explain the differences in the findings. It is likely that dividing socioeconomic level in high and low based on the number of items owned irrespective of type of item is too simplistic. However, a higher number of items owned may indicate a high socioeconomic level as this translates into one having extra money that could be used to buy these items, in addition to food.

All analyses were adjusted for the clustering effect of schools because there were differences in infection levels among schools, a difference that was highly significant for infections with A. lumbricoides and Cryptosporidium spp. [19]. This could be due to the fact that schools had different levels of hygiene practices. Some schools kept readily available water for the children to wash hands after latrine use or before eating, while others did not; and since running water was not available at all times [19], this could have exposed children in some schools to high risk of these infections. However, there was no difference in Giardia infection levels among schools, but this infection was, on the other hand, found to be positively associated with living in a house with corrugated iron sheet. Other types of roofing materials included asbestos, tiles, and grass and there is no clear explanation why corrugated iron sheets should put children at higher risk of being infected with Giardia. However, roofing type gives some indication of socioeconomic level of a household, with tiles being the most expensive type and therefore they are used by those with a high socioeconomic level. Based on the findings from the present study, we cannot make conclusions on the influence of this particular factor on infections. The factors need further exploration with probably a larger sample size.

Municipal water consumption was not associated with any infection, a finding similar to that of Rinne et al. [22]. This is in contrast to other studies that have reported associations between Cryptosporidium spp. infections and drinking municipal water [24]. Owning a toilet and total number of people per household did not present statistically significant associations with any of the infections. Lack of facilities for disposal of faeces is a known risk factor for faecaloral route transmission of infections like those considered in the present study $[25,26]$, and therefore, the present results are in contrast to these findings. However, owning a toilet/latrine may not be the most important aspect in the transmission of infection but how the latrine is used and the hygiene practices by the children after using the latrine. Even though the results were statistically insignificant for the stated factors in the present study, the number of children that were infected was reasonably high for both helminths and the protozoan parasites.

In the second part of the present study, four factors (if parents treated drinking water and the treatment method, 
keeping of animals, and consumption of uncooked vegetables) were assessed for their association with Cryptosporidium spp. and $G$. duodenalis infection. None of these factors were significantly associated with either infection, probably due to the small sample size, which may not permit detection of small risk differences. However, treatment of water and the treatment method are cardinal in the prevention of transmission of these parasites. Both Cryptosporidium spp. and Giardia can survive in chlorinated water $[27,28]$, and municipal water which is mostly used in this neighbourhood is chlorinated and most people do nothing extra to it, for example, boiling. This could be one of the reasons for the high number of cases. Although keeping animals was not a risk factor in present study, contact with animals has been reported as a risk factor $[29,30]$.

Consumption of uncooked vegetables was not a risk factor for any of the infections in the present study and very few children came from homes where consumption of uncooked vegetables was a practice. This can be explained by the fact that, in most of such communities, people normally cook their vegetables and rarely eat raw vegetables/foods. It was observed that they cooked the vegetables for at least five minutes.

\section{Conclusion}

The present findings indicate that level of education and the socioeconomic level of parents have an effect on the occurrence of infection in these preschool children. However, other factors studied need further exploration to clearly understand or assess their influence on parasite infection in the children in these communities.

\section{Conflict of Interests}

The authors declare that there is no conflict of interests regarding the publication of this paper.

\section{Acknowledgments}

The authors are grateful to all study participants and their parents/guardians. Mr. Bright Chulu is also acknowledged for his technical assistance during the laboratory analysis of samples. The study was funded by DBL-Centre for Health Research and Development.

\section{References}

[1] S. Brooker, A. C. A. Clements, and D. A. P. Bundy, "Global epidemiology, ecology and control of soil-transmitted helminth infections," Advances in Parasitology, vol. 62, pp. 221-261, 2006.

[2] WHO, Fighting Disease, Fostering Development, The World Health Report, World Health Organization, Geneva, Switzerland, 1996.

[3] N. R. de Silva, S. Brooker, P. J. Hotez, A. Montresor, D. Engels, and L. Savioli, "Soil-transmitted helminth infections: updating the global picture," Trends in Parasitology, vol. 19, no. 12, pp. 547$551,2003$.
[4] L. R. S. Moraes and S. Cairncross, "Environmental interventions and the pattern of geohelminth infections in Salvador, Brazil," Parasitology, vol. 129, no. 2, pp. 223-232, 2004.

[5] D. W. T. Crompton and L. Savioli, Handbook of Helminthiasis for Public Health, Taylor \& Francis/CRC Press, Boca Raton, Fla, USA, 2007.

[6] P. J. Hotez, D. H. Molyneux, A. Fenwick et al., "Control of neglected tropical diseases," The New England Journal of Medicine, vol. 357, no. 10, pp. 1018-1027, 2007.

[7] R. L. Pullan, J. L. Smith, R. Jasrasaria, and S. J. Brooker, "Global numbers of infection and disease burden of soil transmitted helminth infections in 2010," Parasites and Vectors, vol. 7, no. 1, article 37, 2014.

[8] R. L. Cordell and D. G. Addiss, "Cryptosporidiosis in child care settings: a review of the literature and recommendations for prevention and control," Pediatric Infectious Disease Journal, vol. 13, no. 4, pp. 310-317, 1994.

[9] R. Fayer, "General biology", in Cryptosporidium and Cryptosporidiosis, R. Fayer and L. Xiao, Eds., pp. 1-42, CRC Press, Taylor \& Francis, Boca Raton, Fla, USA, 2nd edition, 2008.

[10] A. Bajer, "Between-year variation and spatial dynamics of Cryptosporidium spp. and Giardia spp. infections in naturally infected rodent populations," Parasitology, vol. 135, no. 14, pp. 1629-1649, 2008.

[11] M. J. G. Farthing, "Clinical aspects of human cryptosporidiosis," Contributions to microbiology, vol. 6, pp. 50-74, 2000.

[12] R. D. Newman, S.-X. Zu, T. Wuhib, A. A. M. Lima, R. L. Guerrant, and C. L. Sears, "Household epidemiology of Cryptosporidium parvum infection in an urban community in Northeast Brazil," Annals of Internal Medicine, vol. 120, no. 6, pp. 500-505, 1994.

[13] M. D. G. C. Pereira, E. R. Atwill, A. P. Barbosa, S. A. E. Silva, and M. T. A. García-Zapata, "Intra-familial and extra-familial risk factors associated with Cryptosporidium parvum infection among children hospitalized for diarrhea in Goiânia, Goiás, Brazil," American Journal of Tropical Medicine and Hygiene, vol. 66, no. 6, pp. 787-793, 2002.

[14] M. D. G. C. Pereira, E. R. Atwill, and A. P. Barbosa, "Prevalence and associated risk factors for Giardia lamblia infection among children hospitalized for diarrhea in Goiânia, Goiás State, Brazil," Revista do Instituto de Medicina Tropical de São Paulo, vol. 49, no. 3, pp. 139-145, 2007.

[15] M. J. G. Farthing, "Giardiasis," in Protozoal Diseases, H. M. Gills, Ed., pp. 562-584, Arnold Publishers, London, UK, 1999.

[16] R. C. A. Thompson, "Giardiasis as a re-emerging infectious disease and its zoonotic potential," International Journal for Parasitology, vol. 30, no. 12, pp. 1259-1267, 2000.

[17] M. Nchito, P. Kelly, S. Sianongo et al., "Cryptosporidiosis in urban Zambian children: an analysis of risk factors," The American Journal of Tropical Medicine and Hygiene, vol. 59, no. 3, pp. 435-437, 1998.

[18] Central Statistical Office (CSO), 2010 Census of Population and Housing Report, Central Statistical Office (CSO), Lusaka, Zambia, 2012.

[19] J. Siwila, I. G. K. Phiri, H. L. Enemark, M. Nchito, and A. Olsen, "Intestinal helminths and protozoa in children in pre-schools in Kafue district, Zambia," Transactions of the Royal Society of Tropical Medicine and Hygiene, vol. 104, no. 2, pp. 122-128, 2010.

[20] J. Siwila, I. G. K. Phiri, H. L. Enemark, M. Nchito, and A. Olsen, "Seasonal prevalence and incidence of Cryptosporidium spp. and Giardia duodenalis and associated diarrhoea in children 
attending pre-school in Kafue, Zambia," Transactions of the Royal Society of Tropical Medicine and Hygiene, vol. 105, no. 2, pp. 102-108, 2011.

[21] T. B. de Carvalho, L. R. de Carvalho, and L. M. Mascarini, "Occurrence of enteroparasites in day care centers in Botucatu (São Paulo State, Brazil) with emphasis on Cryptosporidium sp., Giardia duodenalis and Enterobius vermicularis," Revista do Instituto de Medicina Tropical de Sao Paulo, vol. 48, no. 5, pp. 269-273, 2006.

[22] S. Rinne, E. J. Rodas, R. Galer-Unti, N. Glickman, and L. T. Glickman, "Prevalence and risk factors for protozoan and nematode infections among children in an Ecuadorian highland community," Transactions of the Royal Society of Tropical Medicine and Hygiene, vol. 99, no. 8, pp. 585-592, 2005.

[23] S. K. Menzies, A. Rodriguez, M. Chico et al., "Risk factors for soil-transmitted helminth infections during the first 3 years of life in the tropics; findings from a birth cohort," PLoS Neglected Tropical Diseases, vol. 8, no. 2, Article ID e2718, 2014.

[24] C. T. Leach, F. C. Koo, T. L. Kuhls, S. G. Hilsenbeck, and H. B. Jenson, "Prevalence of Cryptosporidium parvum infection in children along the Texas-Mexico border and associated risk factors," The American Journal of Tropical Medicine and Hygiene, vol. 62, no. 5, pp. 656-661, 2000.

[25] E. Cifuentes, M. Gomez, U. Blumenthal et al., "Risk factors for Giardia intestinalis infection in agricultural villages practicing wastewater irrigation in Mexico," The American Journal of Tropical Medicine and Hygiene, vol. 62, no. 3, pp. 388-392, 2000.

[26] S. Esrey, J. Collett, M. O. Miliotis, H. J. Koornhof, and P. Makhale, "The risk of infection from Giardia duodenalis due to drinking water supply, use of water and latrines among pre-school children in rural Lesotho," International Journal of Epidemiology, vol. 18, no. 1, pp. 248-253, 1989.

[27] G. F. Craun, "Waterborne giardiasis in the United States: a review," The American Journal of Public Health, vol. 69, no. 8, pp. 817-819, 1979.

[28] R. Fayer, C. A. Speer, and J. P. Dubey, "The general biology of Cryptosporidium," in Cryptosporidium and Cryptosporidiosis, $\mathrm{R}$. Fayer, Ed., pp. 1-41, CRC Press, Boca Raton, Fla, USA, 1997.

[29] J.-R. Yu, J.-K. Lee, M. Seo et al., "Prevalence of cryptosporidiosis among the villagers and domestic animals in several rural areas of Korea," The Korean Journal of Parasitology, vol. 42, no. 1, pp. 1-6, 2004.

[30] J. Siwila, I. G. K. Phiri, J. Vercruysse et al., "Asymptomatic cryptosporidiosis in Zambian dairy farm workers and their household members," Transactions of the Royal Society of Tropical Medicine and Hygiene, vol. 101, no. 7, pp. 733-734, 2007. 


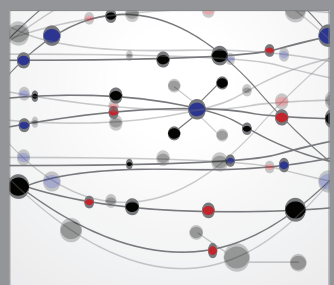

The Scientific World Journal
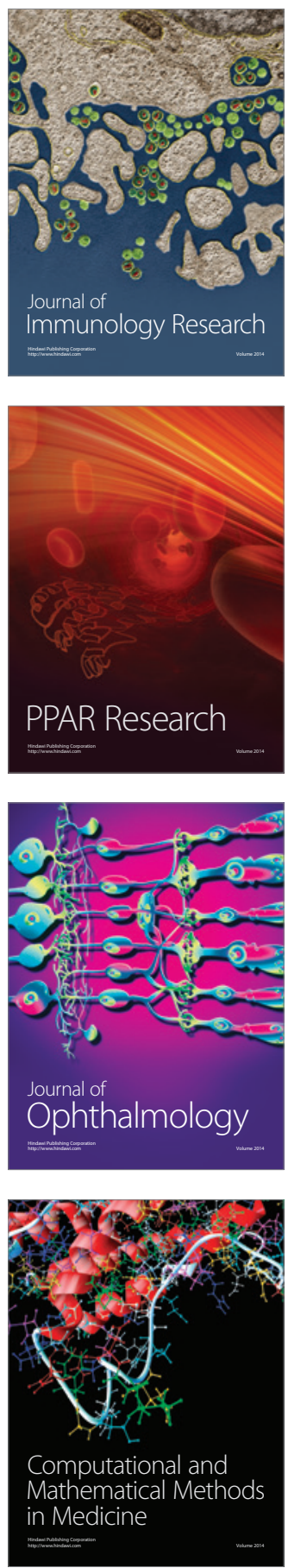

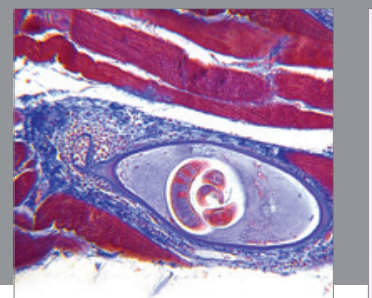

Gastroenterology

Research and Practice
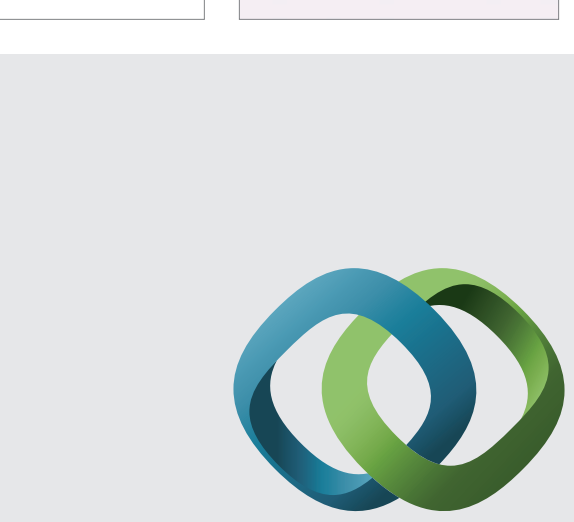

\section{Hindawi}

Submit your manuscripts at

http://www.hindawi.com
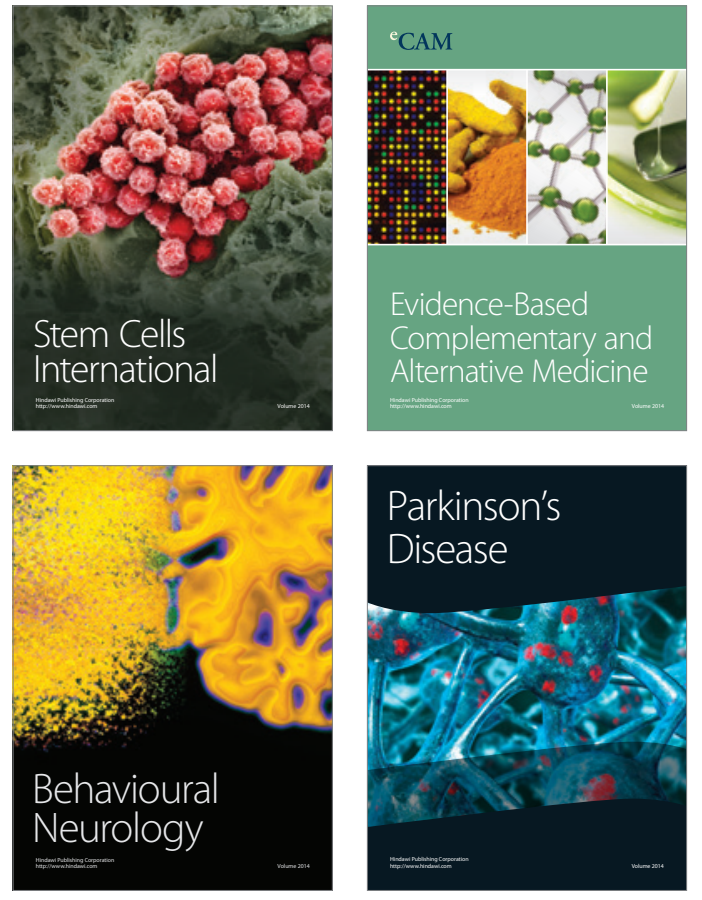
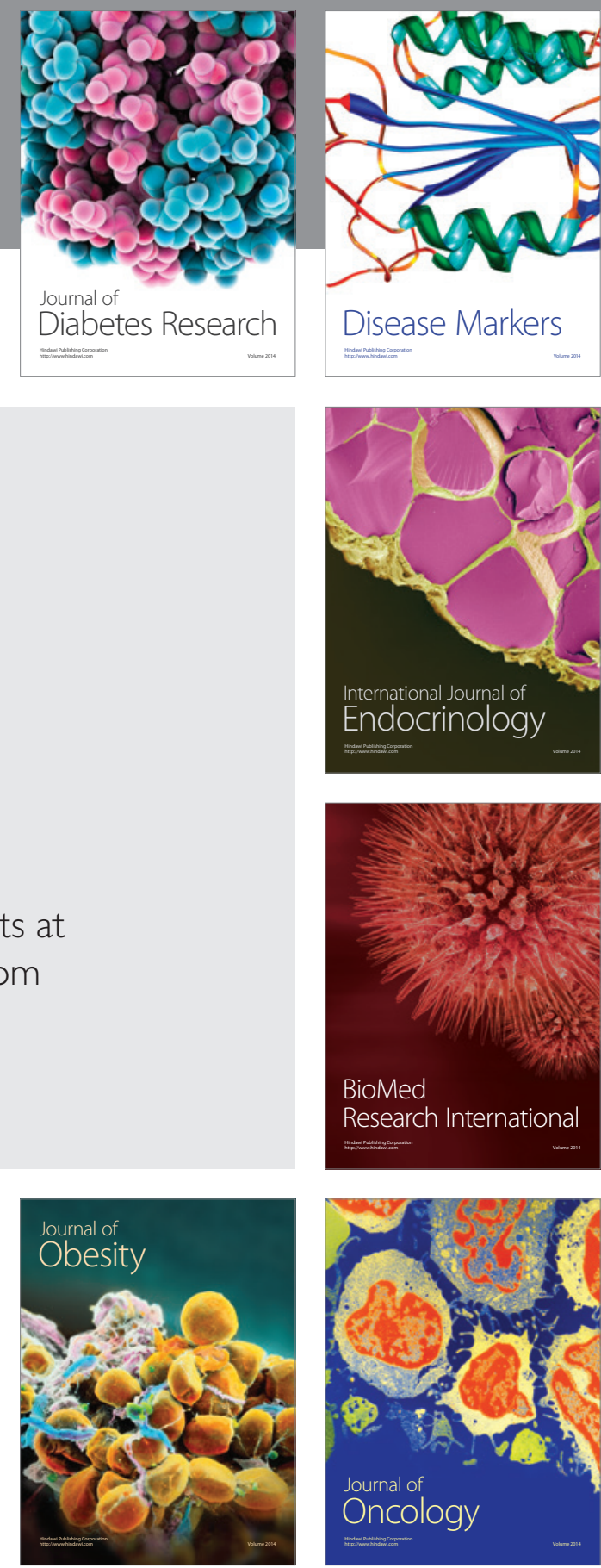

Disease Markers
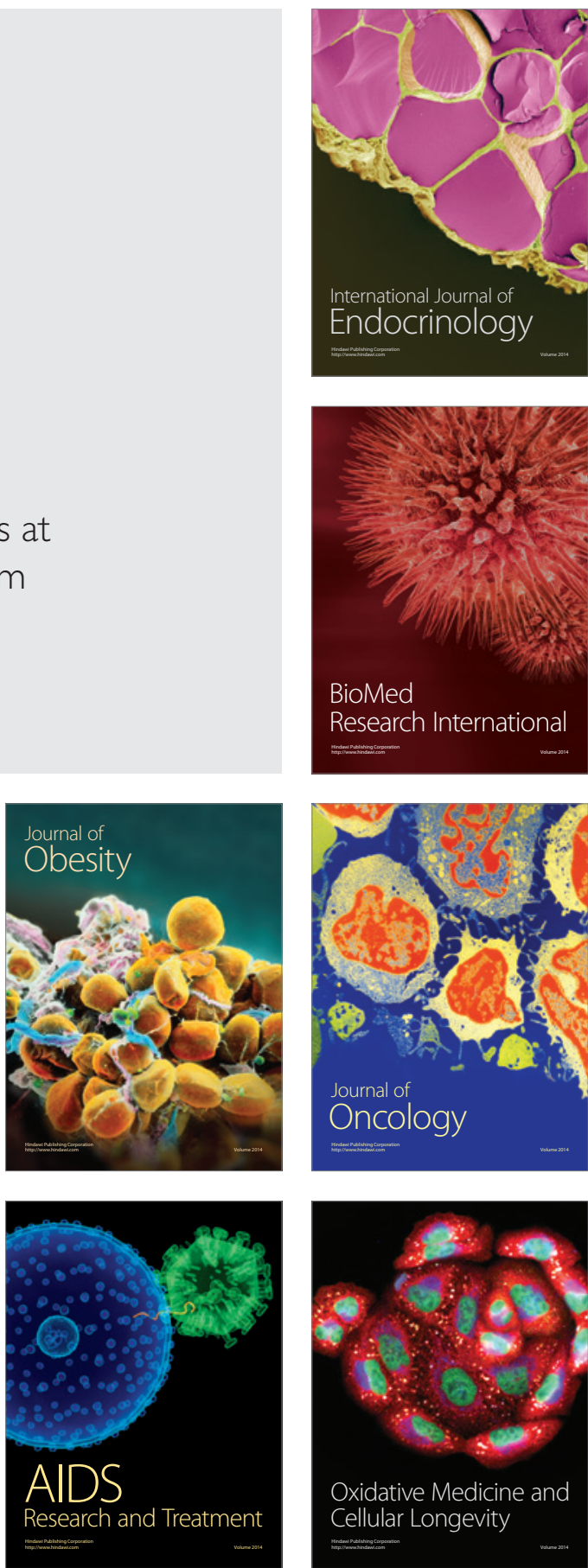